\title{
Development of calving ease evaluations for UK Holstein-Friesian cows
}

\author{
E Wall $^{1}, \mathrm{R}_{\text {Mrode }}{ }^{1}, \mathrm{G}_{\text {Banos }}^{2}$, M Coffey $^{1}$ \\ ${ }^{1} \mathrm{SAC}$, Edinburgh, United Kingdom, ${ }^{2}$ Aristotle University, Thessaloniki, Greece \\ Email: eileen.wall@sac.ac.uk
}

Introduction The ease of calving influences the economics of a cow/calf enterprise through increased calf death loss, increased labour and veterinary costs, reduced subsequent reproductive performance of the cow, potential loss of the cow, and reduced milk production. McGuirk et al. (2007) estimated that a slightly difficult calving cost approximately $£ 110$ and a seriously difficult calving cost $£ 350-£ 400$. Many countries around the world undertake genetic evaluations for calving ease (CE). The aim of this project was to develop routine national CE evaluations for UK dairy cattle.

Materials and methods Data were taken from UK milk recording organisations, and covers farmer recorded CE as well as data collected as part of the progeny test scheme. Genetic parameters for CE were estimated using ASReml (version 2.00, 2006) considering a direct and indirect effect. Fixed effects in the model include herd-year, month of calving, lactation number, calf sex and interaction between lactation number and calf

Direct $\square$ Maternal

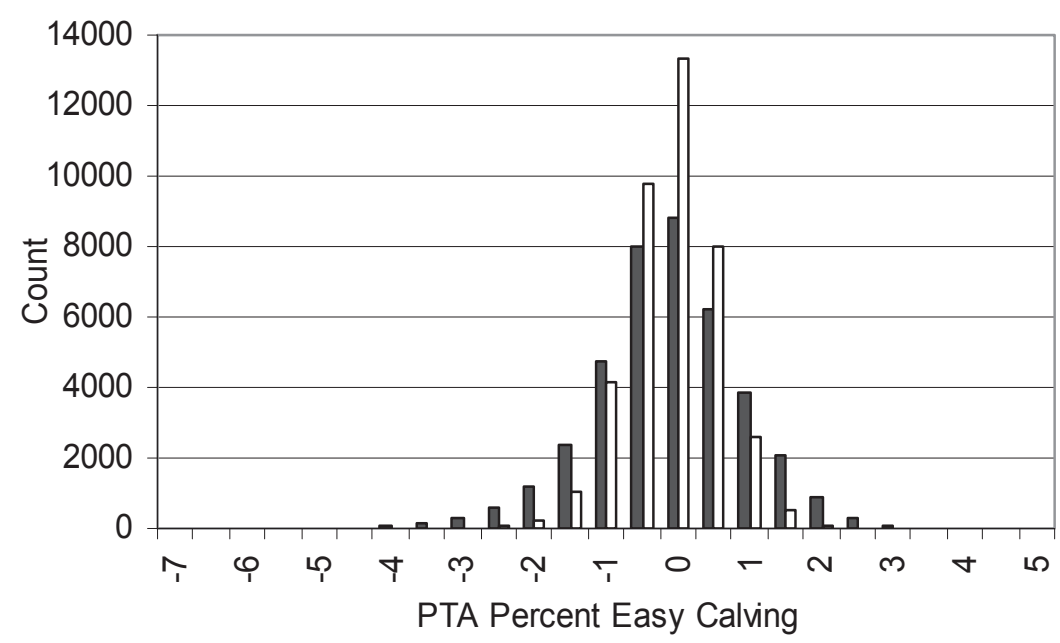

Figure 1. Distribution of calving ease PTAs (direct and maternal) sex. Age and percentage Holstein were fitted as linear regressions. A random effect of service sire was fitted to estimate direct CE predicted transmitting ability (PTA) and random effect of maternal grandsire fitted for indirect CE PTA, with a covariance between the 2 effects also fitted. A maternal CE PTA was then computed as the indirect CE PTA minus one quarter of the direct $\mathrm{CE}$ PTA. The direct CE PTA relates to the ease with which a bull's calves are expected to be born and the maternal calving ease PTA relates to the ease with which the bull's daughters are likely to give birth. Bull PTAs for direct and maternal $\mathrm{CE}$ were submitted to a test multiple across country evaluation (MACE) of calving traits performed by the Interbull Centre (Uppsala, Sweden), thus allowing UK evaluation of CE to be compared to evaluations from other countries on the UK scale. A data and pedigree file were extracted in September 2009 and contained almost 400,000 calving records, representing almost 6,000 sires.

Results The data approximately spanned 15 years, however, the majority of the data falls after 1999. Overall, 84\% of calvings were classed as "easy calving". For first calving cows a total of $74 \%$ calvings were classed as "easy" and $85 \%$ of later calvings. The genetic analysis showed that the heritability for calving ease was low (0.066 and 0.040 for direct and indirect effects respectively with a genetic correlation of -0.685). Figure 1 shows that the calving ease PTAs were expressed as percent easy calving and centred around zero, with a positive value being favourable (i.e., less difficult calvings). There was no evidence of a genetic trend in either direct or maternal CE PTAs. The across country genetic correlations for the MACE run for direct and maternal CE were in line with other countries and suggest that UK CE PTAs would be suitable for an international MACE evaluation. The genetic correlations between countries for the direct calving trait averaged of 0.80 and ranged from 0.619 (with Hungary) to 0.944 (with Canada). The genetic correlations between countries for the maternal calving trait was a little lower with an average of 0.69 and ranged from 0.561 (with Hungary) to 0.839 (with France). These correlations with other countries are good, particularly for such low heritability traits.

Conclusions Having calving ease proofs available will help farmers identify bulls that are genetically good (or bad) for calving performance. This may be of particular importance when choosing bulls to use (or avoid) on heifers to avoid the costs associated with losses in production, fertility and potentially cow/calf losses.

Acknowledgements The authors gratefully acknowledge funding from Defra LINK, Scottish Government, DairyCo, National Milk Records, Cattle Information Services, Holstein UK, Genus ABS and Cogent Breeding

\section{References}

McGuirk, B.J., R. Forsyth, and H. Dobson. 2007. The Veterinary Record 161, 685-687. 